\title{
Cervicovaginal Microbiota Predicts Neisseria gonorrhoeae Clinical Presentation
}

\author{
Angela Lovett ${ }^{1}$, Arlene C. Seña ${ }^{2,3}$, Andrew N. Macintyre ${ }^{4}$, Gregory D. Sempowski ${ }^{4}$, \\ Joseph A. Duncan ${ }^{1,2,3,5 t}$ and Andreea Waltmann ${ }^{3 * t}$ \\ ${ }^{1}$ Department of Pharmacology, University of North Carolina at Chapel Hill, Chapel Hill, NC, United States, ${ }^{2}$ Division \\ of Infectious Diseases, Department of Medicine, University of North Carolina at Chapel Hill, Chapel Hill, NC, United States, \\ ${ }^{3}$ Institute for Global Health and Infectious Diseases, University of North Carolina at Chapel Hill, Chapel Hill, NC, \\ United States, ${ }^{4}$ School of Medicine and Duke Human Vaccine Institute, Duke University, Durham, NC, United States, \\ ${ }^{5}$ Lineberger Comprehensive Cancer Center, University of North Carolina at Chapel Hill, Chapel Hill, NC, United States
}

\section{OPEN ACCESS}

Edited by:

Neeraj Chauhan,

Rutgers Biomedical and Health

Sciences, United States

Reviewed by:

Tatsuo Suzutani,

Fukushima Medical University, Japan

Erica Boldenow,

Calvin University, United States

${ }^{*}$ Correspondence:

Andreea Waltmann

waltmann@email.unc.edu

${ }^{\dagger}$ These authors have contributed equally to this work and share senior

authorship

Specialty section

This article was submitted to Infectious Agents and Disease, a section of the journa

Frontiers in Microbiology

Received: 06 October 2021 Accepted: 13 December 2021

Published: 10 February 2022

Citation:

Lovett A, Seña AC, Macintyre AN,

Sempowski GD, Duncan JA and

Waltmann A (2022) Cervicovaginal

Microbiota Predicts Neisseria

gonorrhoeae Clinical Presentation.

Front. Microbiol. 12:790531.

doi: 10.3389/fmicb.2021.790531
Neisseria gonorrhoeae infection of the female lower genital tract can present with a spectrum of phenotypes ranging from asymptomatic carriage to symptomatic cervical inflammation, or cervicitis. The factors that contribute to the development of asymptomatic or symptomatic infections are largely uncharacterized. We conducted a pilot study to assess differences in the cervicovaginal microbial community of patients presenting with symptomatic vs. asymptomatic $N$. gonorrhoeae infections to a sexually transmitted infections (STI) clinic. DNA was isolated from cervicovaginal swab specimens from women who tested positive for N. gonorrhoeae infection using a clinical diagnostic nucleic acid amplification test. We performed deep sequencing of $16 \mathrm{~S}$ ribosomal RNA gene amplicons, followed by microbiome analyses with QIIME, and species-specific real-time PCR to assess the composition of microbial communities cohabitating the lower genital tract with the infecting $N$. gonorrhoeae. Specimens collected from asymptomatic individuals with $N$. gonorrhoeae infection and no co-infection with Chlamydia trachomatis and/or Trichomonas vaginalis carried Lactobacillus-dominant microbial communities more frequently than symptomatic patients without co-infection. When compared to asymptomatic individuals, symptomatic women had microbial communities characterized by more diverse and heterogenous bacterial taxa, typically associated with bacterial vaginosis (BV) [Prevotella, Sneathia, Mycoplasma hominis, and Bacterial Vaginosis-Associated Bacterium-1 (BVAB1)/“Candidatus Lachnocurva vaginae"]. Both symptomatic and asymptomatic N. gonorrhoeae patients with additional STI co-infection displayed a BVlike microbial community. These findings suggest that Lactobacillus-dominant vaginal microbial community may protect individuals from developing symptoms during lower genital tract infection with $N$. gonorrhoeae. 


\section{INTRODUCTION}

Neisseria gonorrhoeae is a sexually transmitted bacterial pathogen responsible for 90 million infections globally each year (Rowley et al., 2019). N. gonorrhoeae is a strictly human pathogen and infections are typically localized to the lower genital tract. Although acute symptomatic infection is often recognized and treated with antibiotic therapy, a surprisingly large proportion of $N$. gonorrhoeae infections are asymptomatic (Handsfield et al., 1974; Platt et al., 1983; Sandstrom et al., 1984). Upwards of 50\% of lower genital tract infections in females are asymptomatic (Kent et al., 2005; Lovett and Duncan, 2018). While the prevailing dogma is that male urethral infections are symptomatic, compelling reports have documented that asymptomatic genital gonorrhea is prevalent in both biological sexes and across a wide range of settings (Handsfield et al., 1974; Potterat et al., 1987; Sherrard and Barlow, 1996; Hazel et al., 2014; Ong et al., 2017; Martin-Sanchez et al., 2020). Asymptomatic infection is not without consequence. Untreated asymptomatic infections can ascend to the upper genital tract leading to health complications including pelvic inflammatory disease and infertility in women (Wiesenfeld et al., 2012; Reekie et al., 2018, 2019). Asymptomatic genital $N$. gonorrhoeae poses a risk of onward transmission to sex partners and ascending infection. Mathematical models of gonorrhea transmission have confirmed unequivocally the significant contribution of subclinical infections in maintaining community transmission (Hazel et al., 2015). The determinants and mechanisms that underlie asymptomatic and symptomatic gonorrhea infection are unknown. This knowledge gap greatly hinders efforts to develop new strategies for gonorrhea control.

Symptomatic N. gonorrhoeae infection most commonly leads to localized host inflammation at the site of infection, urethritis in males, and cervicitis in females. $N$. gonorrhoeae itself is resistant to many host antimicrobial responses, which may contribute to its ability to cause infection under these conditions of localized inflammation. During an infection, $N$. gonorrhoeae must compete with the natural microbial community at the mucosal surface to establish infection (Aroutcheva et al., 2001). Cervicovaginal microbial communities play an important role in sexual and reproductive outcomes, including protection from pathogens, as the composition of the cervicovaginal microbiota has been shown to modify susceptibility to several sexually transmitted pathogens (STI) (Sha et al., 2005; Coleman et al., 2007; Atashili et al., 2008; Masson et al., 2014, 2015; Anahtar et al., 2015; McClelland et al., 2018). For example, human vaginal microbiota dominated by Lactobacillus crispatus is associated with reduced risk of acquisition of STI, like HIV (Borgdorff et al., 2014; Gosmann et al., 2017; van der Veer et al., 2017; Tamarelle et al., 2019). In addition, women with clinically apparent bacterial vaginosis (BV), a clinical condition characterized by depleted levels of Lactobacillus species and an increased abundance of diverse groups of facultative anaerobes, have an increased risk of acquiring and transmitting STI, including $N$. gonorrhoeae (Wiesenfeld et al., 2003; Gallo et al., 2012; Borgdorff et al., 2014; Bautista et al., 2017) and at an increased risk of adverse reproductive and obstetric outcomes (Brotman, 2011; Elovitz et al., 2019; Fettweis et al., 2019), irrespective of whether the $\mathrm{BV}$ is symptomatic or not (Atashili et al., 2008; Brotman, 2011;
McKinnon et al., 2019). These factors indicate a mechanistic contribution of $L$. crispatus to protection from STI, presumably through the production of lactic acid and thus the maintenance of a low-pH vaginal microenvironment (Tuddenham et al., 2021). The reasons why the microbiota of some women is dominated by Lactobacillus species, whereas that of others becomes dominated by anaerobes are not completely understood.

Molecular definitions of the cervicovaginal microbiota of reproductive age women, with respect to microbial composition and diversity, are now standard (Ravel et al., 2011; Anahtar et al., 2015; Gosmann et al., 2017). Using 16S rRNA sequencing or metagenomics, distinct cervicovaginal microbial community types (CTs) have been classified (Ravel et al., 2011; Anahtar et al., 2015; Gosmann et al., 2017). The "optimal types" CT1 and CT2 are dominated by L. crispatus and L. gasseri, respectively. The other two Lactobacillus-dominant molecular community types are L. iners (CT3) and L. jensenii (CT5). Notably, not all Lactobacillus-dominant types are equal in their protective effect against STI, as $L$. iners-dominated vaginal microbiotas may actually place patients at higher risk of STI infection, like chlamydia or HIV, when compared to L. crispatus-dominant microbiotas (Gosmann et al., 2017; van der Veer et al., 2017; Tamarelle et al., 2019). Finally, CT4 communities are characterized by a diverse and heterogenous group of anaerobes (e.g., Atopobium, Prevotella, Dialister, Gardnerella, Megasphaera, Peptoniphilus, Sneathia, Eggerthella, Aerococcus, Finegoldia, and Mobiluncus; Ravel et al., 2011) and this vaginal environment is a significant risk factor for having clinically diagnosed BV (Amsel et al., 1983; Srinivasan et al., 2012; Peebles et al., 2019) and is termed molecular BV (McKinnon et al., 2019).

Studies examining the impact of vaginal microbiomes on inflammatory states found that women with clinical BV or molecular BV (i.e., CT4 microbial communities) had higher cervicovaginal levels of pro-inflammatory cytokines (IL- $1 \alpha$, IL$1 \beta$, IL-6, IL-12, and IL-8) than BV-negative or Lactobacillusdominant women, respectively (Masson et al., 2014; Gosmann et al., 2017; Joag et al., 2019). Notably, the more the vaginal microbiota shifts away from a state dominated by L. crispatus toward dysbiosis (i.e., toward CT3 and CT4 types), the more marked the inflammation (Cohen et al., 2010; Anahtar et al., 2015; Lennard et al., 2018), independently of concurrent STIs, including gonorrhea (Anahtar et al., 2015). This indicates that the variations in vaginal microbial diversity that are common in women with BV could influence inflammatory responses that characterize symptomatic $N$. gonorrhoeae infection.

We sought to understand whether differences in microbial composition of the genital tract were associated with symptomatic or asymptomatic presentation of N. gonorrhoeae infection, by utilizing $16 \mathrm{~S}$ ribosomal RNA (rRNA) amplicon deep sequencing of clinician-collected cervicovaginal specimens from females diagnosed with gonorrhea.

\section{MATERIALS AND METHODS}

\section{Study Population and Sample Collection}

Specimens used in this study were remnant specimens collected from female patients that attended a public STI clinic located 
in Durham, North Carolina in 2011 and tested positive for $N$. gonorrhoeae using the clinical diagnostic assay Aptima Combo $2^{\circledR}$ assay (for CT/NG) by Hologic. Clinician-collected cervicovaginal swabs used for diagnosis were collected as per routine care prior to any treatment. The age, race, reported symptoms, and diagnosis for each study subject were linked to each specimen by a study clinician when a positive specimen was identified. The de-identified remnant cervical swab samples were stored in Aptima buffer in their respective transport tubes at $-80^{\circ} \mathrm{C}$ until DNA extraction was performed.

\section{DNA Extraction}

Two hundred microliters of Aptima buffer from each sample were transferred to sterile 2 -ml tubes containing $200 \mathrm{mg}$ of $\leq 100$ $\mu \mathrm{m}$ glass beads (Sigma), $0.3 \mathrm{ml}$ of $20 \mathrm{mg} / \mathrm{ml}$ lysozyme solution (Thermo Fisher), and $0.3 \mathrm{ml}$ of Qiagen ATL buffer. Bead-beating was then carried out for $10 \mathrm{~min}$ in a Qiagen TissueLyser II at $30 \mathrm{~Hz}$ to ensure optimal DNA yield from Gram-positive bacteria. Subsequently, samples were incubated at $37^{\circ} \mathrm{C}$ for $30 \mathrm{~min}$. After a brief centrifugation, supernatants were aspirated and transferred to a new sterile tube with Qiagen AL buffer containing Proteinase $\mathrm{K}(600 \mathrm{IU} / \mu \mathrm{l})$. Samples were then incubated at $70^{\circ} \mathrm{C}$ for $10 \mathrm{~min}$. DNA was purified using a standard on-column purification method using Zymo-spin mini columns and Qiagen buffers AW1 and AW2 as washing agents. DNA was eluted in $100 \mu \mathrm{l}$ of $10 \mathrm{mM}$ Tris ( $\mathrm{pH} 8.0)$.

\section{S Ribosomal RNA Gene Sequencing}

For amplicon library preparation, we used fusion primers composed of Ion Torrent adapter $5^{\prime}$ CCATCTCATCCCTGCGTGTCTCCGACTCAG-3' for the forward primer and 5'-CCTCTCTATGGGCAGTCGGTGAT$3^{\prime}$ for the reverse primer, and universal bacterial primer 8F $\quad 5^{\prime}$-AGAGTTTGATCCTGGCTCAG-3' and 338R $5^{\prime}$ GCTGCCTCCCGTAGGAGT-3'. The forward primer also included a 10-bp IonXpress ${ }^{\mathrm{TM}}$ barcode, unique to each sample. Each bacterial DNA sample was run in duplicate in a 25- $\mu 1$ PCR reaction containing: $4 \mu \mathrm{l}$ of $5 \times$ MyTaq Reaction Buffer (Bioline); $0.6 \mu \mathrm{l}$ each of $15 \mu \mathrm{M}$ Forward Primer and $15 \mu \mathrm{M}$ Reverse Primer (Integrated DNA Technologies); $0.5 \mu$ l of MyTaq HS DNA Polymerase (Bioline); 100 ng of template DNA; and water to $25 \mu \mathrm{l}$. Samples were denatured at $94^{\circ} \mathrm{C}$ for $5 \mathrm{~min}$, followed by 35 cycles of $94^{\circ} \mathrm{C}$ for $45 \mathrm{~s}, 55^{\circ} \mathrm{C}$ for $45 \mathrm{~s}$, and $72^{\circ} \mathrm{C}$ for $90 \mathrm{~s}$, followed by an extension at $72^{\circ} \mathrm{C}$ for $10 \mathrm{~min}$ and a $4^{\circ} \mathrm{C}$ hold. Each sample was visualized on a $2 \%$ agarose gel. Bands were excised and duplicate bands were combined into one tube. Gel purification was performed using the Qiagen Gel Extraction Kit (Qiagen) according to the manufacturer's protocol. Samples were quantified using an Agilent 2100 Bioanalyzer (Agilent). Quantification information was used to create a library by combining equimolar concentrations of each sample. The prepared library was sequenced on the Ion Torrent PGM Instrument (Life Technologies) according to the manufacturer's protocol at UNC-CH High Throughput Sequencing Facility.

\section{Sequence Data Analysis}

Sequencing output was demultiplexed and the resulting paired-end reads were joined using the QIIME 1.9.0
(Caporaso et al., 2010b) by invocation of fastq-join with the default parameters. Index and linker primer sequences were trimmed, and the reads were subsequently filtered for quality using a sliding window of 50 bases, moving by five bases, requiring an average quality score of 20 or above. Quality control of both raw and processed sequencing reads was verified by FastQC (FastQC, 2015). Sequences were clustered into operational taxonomic units (OTU) based on the de novo OTU picking algorithm using the QIIME implementation of UCLUST (Edgar, 2010) at a similarity threshold of 97\%. OTUs identified as chimeric by vsearch (Rognes et al., 2016) of the ChimeraSlayer "gold" reference database (Haas et al., 2011) and those composed of a single read (singletons) were eliminated. The remaining OTUs were assigned taxonomic identifiers with respect to the Greengenes database (DeSantis et al., 2006), and their sequences were aligned using template alignment through PyNAST (Caporaso et al., 2010a), and a phylogenetic tree was built with FastTree 2.1.3 (Price et al., 2010). If after the Greengenes taxonomic assignment a taxon of interest was ambiguous at the genus level or when putative species taxonomy was sought, we consulted the $16 \mathrm{~S}$ sequences in the National Center for Biotechnology Information (NCBI) GenBank repository with the Basic Local Alignment Search Tool (BLAST) (Altschul et al., 1990) and/or with the multiple sequence comparison by log-expectation method (MUSCLE) implemented in Geneious using reference genomes.

\section{Microbiome Analyses}

Alpha diversity was measured by three different metrics (Chao1; and observed species; phylogenetic diversity, PD) using QIIME. Beta diversity estimates were calculated within QIIME using weighted and unweighted Unifrac distances (Lozupone and Knight, 2005) between samples. Results were summarized and visualized through principal coordinate analysis (PCoA) in QIIME. Cervicovaginal community types (CTs) were assigned using established definitions (Ravel et al., 2011; Anahtar et al., 2015; Gosmann et al., 2017) based on diversity and relative abundance of bacterial taxa. These definitions classify samples with relative majority abundance assigned to $L$. crispatus, L. gasseri, L. iners, or L. jensenii as CT1, CT2, CT3, and CT5, respectively. According to the same definitions, low Lactobacillus communities comprising a diverse and heterogenous group of anaerobes (e.g., Atopobium, Prevotella, Dialister, Gardnerella, Megasphaera, Peptoniphilus, Sneathia, Eggerthella, Aerococcus, Finegoldia, and Mobiluncus are classified as CT4 or "molecular bacterial vaginosis") (McKinnon et al., 2019).

\section{Microbial DNA qPCR Array}

The Vaginal Flora Microbial DNA qPCR Array (Cat. no. 330261 BAID-1902Y, Qiagen) was used for vaginal microbiome profiling. Each specimen was processed and run on the 96-well array plate format. The array contained assays for the detection of 90 microbial species, 2 Pan bacteria controls (Pan Bacteria 1, Pan Bacteria 3), 1 Pan Fungi control (Pan Aspergillus/Candida), 2 host controls (Hs/Mm.GAPDH Hs/Mm.HBB1), and a positive PCR control (PPC). Five hundred nanograms of genomic DNA was mixed with 1,275 $\mu$ l of microbial qPCR Mastermix and water as needed to bring the total volume to $2,550 \mu \mathrm{l}$, using the 
manufacturer's instructions. Individual reaction mix aliquots of $25 \mu \mathrm{l}$ were added to each well of the plate, and the array plate was tightly sealed, centrifuged at 1,000 rpm for $1 \mathrm{~min}$, and loaded onto the Real-Time PCR machine. PCR was performed with an initial PCR activation step at $95^{\circ} \mathrm{C}$ for $10 \mathrm{~min}$, followed by 2-step cycling of denaturation for $15 \mathrm{~s}$ at $95^{\circ} \mathrm{C}$, with annealing and extension for $2 \mathrm{~min}$ at $60^{\circ} \mathrm{C}$ for 40 cycles. The CT values for each well were imported into the Microbial DNA qPCR Array Excel template (Qiagen) for analysis. The $\triangle \mathrm{CT}$ between the patient sample DNA and no DNA template negative control was calculated for each set of species-specific primer sets, following manufacturer's instructions for analysis. A species was reported as "present, + " if $\Delta \mathrm{CT}$ was $>3$, an eightfold increase in signal over background.

\section{Statistical Analyses}

Statistical analyses were performed in PRISM 9 or STATA 16. Differences in donor characteristics and between sample groups were investigated using the Fisher's exact test. We compared $\alpha$-diversity between sample groups with non-parametric twosample $t$-tests using 1,000 Monte Carlo permutations to calculate the $p$-values. To test whether sample groups were statistically different, we used non-parametric ANOSIM (ANalysis Of Similarities) tests and non-parametric two-sample $t$-tests with 1,000 Monte Carlo permutations to derive $p$-values implemented in QIIME. For comparisons between multiple groups, one-way ANOVA was used, correcting for multiple comparisons with Tukey post hoc tests.

\section{RESULTS}

\section{Cohort Characteristics of Neisseria gonorrhoeae-Infected Women}

In this pilot study, we used remnant nucleic acid material from cervical swabs collected from a convenience sample of 19 women deemed to be N. gonorrhoeae-positive by Aptima clinical diagnostic testing. Of these, ten individuals reported symptoms to the provider (defined as symptomatic) and nine did not (defined as asymptomatic) (Table 1). The reported symptoms at the time of cervical swab sampling included vaginal discharge $(9 / 10,90.0 \%)$, genital irritation $(1 / 10,10.0 \%)$, and dysuria $(2 / 10,20 \%)$. There was a trend for younger women to report symptoms $(p=0.090)$. Of the 19 specimens, 17 $(89.5 \%)$ were collected from women who identified as having African American race. Among the African American women, the proportion of symptomatic and asymptomatic individuals was comparable $(p=0.211)$. The presence or absence of C. trachomatis, another STI pathogen, was assessed by NAAT testing in conjunction with clinical $N$. gonorrhoeae testing, and no difference in $C$. trachomatis prevalence was observed between asymptomatic and symptomatic presentation $(p=0.590)$.

Since other STI pathogens could also be responsible for causing lower genital tract symptoms (e.g., Trichomonas vaginalis or Mycoplasma genitalium), we used a commercial microbial qPCR array to test for the presence of other STI pathogens (Table 2). Specimens from two women did not provide evaluable results due to insufficiently recovered DNA material. Among
TABLE 1 | Study population characteristics at baseline.

\begin{tabular}{lccc}
\hline $\begin{array}{l}\text { Baseline } \\
\text { characteristics }\end{array}$ & Symptomatic & Asymptomatic & p-value \\
\cline { 2 - 3 } & $\boldsymbol{n = 1 0}$ & $\boldsymbol{n}=\mathbf{9}$ & \\
\hline Age, mean (range) & $21.1(15-37)$ & $26.6(16-40)$ & 0.09 \\
Race $(n)$ & Black (10) & Black (7) & n/a \\
& Latina (0) & Latina (1) & \\
Symptoms (\%) & White (0) & White (1) & \\
& Vaginal discharge (90.0) & None (100.0) & n/a \\
& Genital irritation (10.0) & & \\
& Dysuria (20.0) & &
\end{tabular}

The age, race, and self-reported symptoms of 19 women positive for N. gonorrhoeae infection by clinical test who presented at a local STI clinic are provided.

the 17 specimens that gave analyzable results on this array, 6 of $7(85.7 \%)$ asymptomatic specimens and 8 of $10(80.0 \%)$ symptomatic specimens had detectable Neisseria species DNA (Table 2). Because these specimens all tested positive for $N$. gonorrhoeae using the Aptima Combo 2, these results indicate that the sensitivity of the microbial qPCR array may be lower for detecting $N$. gonorrhoeae in this specimen type than the Aptima Combo 2. The technical sensitivity of the Aptima assay for detection of $N$. gonorrhoeae is reported as 50 colony-forming units (Aptima ${ }^{\circledR} \mathrm{G}-\mathrm{P}$ ), while the qPCR array is reported to be less than 100 copies of the $16 \mathrm{~S}$ genomic target (Qiagen, 2021), which would correlate with 25 bacterial cells or colonyforming units. However, the potential interference of materials from clinical specimens is not documented for the qPCR array, which is not approved for clinical diagnostic purposes, while the published sensitivity and specificity of the Aptima assay for the detection of $N$. gonorrhoeae in clinical specimens are 97.7 and 99.0\%, respectively (Hologic, 2016). C. trachomatis was detected in three of three specimens that were positive by Aptima Combo 2 test and had evaluable qPCR results in the qPCR array (Table 2). T. vaginalis was detected in 4 of 10 (40.0\%) evaluable symptomatic individuals and 2 of 7 (28.6\%) asymptomatic individuals (Table 2). M. genitalium was not detected by qPCR array in any of the specimens (Table 2). When accounting for both clinical $C$. trachomatis testing by Aptima Combo 2 and real-time PCR array results, the proportion of STI co-infection with $C$. trachomatis or $T$. vaginalis was not significantly different between symptomatic $(5 / 10,50.0 \%)$ and asymptomatic $(5 / 9,55.6 \%)$ individuals $(p=0.625)$. Because coinfection with other STI pathogens was not associated with symptomatic presentation, we next sought to assess whether the non-STI vaginal microbial community was associated with the presence or absence of symptoms.

\section{Neisseria spp. Abundance Represents a Small Proportion of Bacterial Communities in Both Symptomatic and Asymptomatic Patients}

The genital microbial community of the 19 study participants was characterized with $16 \mathrm{~S}$ amplicon deep sequencing. A total 
TABLE 2 | Results of clinical Aptima (NAAT) test results and microbial DNA real-time PCR (qPCR) array.

\begin{tabular}{|c|c|c|c|c|c|c|c|c|c|c|c|c|c|c|c|c|c|c|c|}
\hline \multirow{3}{*}{$\begin{array}{l}\text { Clinical test } \\
\text { Aptima GC }\end{array}$} & \multicolumn{9}{|c|}{ N. gonorrhoeae only } & \multicolumn{10}{|c|}{ N. gonorrhoeae and STI co-infections } \\
\hline & \multicolumn{4}{|c|}{ Asymptomatic } & \multicolumn{5}{|c|}{ Symptomatic } & \multicolumn{5}{|c|}{ Asymptomatic } & \multicolumn{5}{|c|}{ Symptomatic } \\
\hline & + & + & + & + & + & + & + & + & + & + & + & + & + & + & + & + & + & + & + \\
\hline Aptima CT & - & - & - & - & - & - & - & - & - & - & + & + & + & - & - & + & - & + & - \\
\hline \multicolumn{20}{|l|}{ qPCR } \\
\hline N. gonorrhoeae & + & + & + & + & + & + & - & + & + & + & + & $\mathrm{n} / \mathrm{a}$ & $\mathrm{n} / \mathrm{a}$ & - & + & + & - & + & + \\
\hline C. trachomatis & - & - & - & - & - & - & - & - & - & - & + & $\mathrm{n} / \mathrm{a}$ & $\mathrm{n} / \mathrm{a}$ & - & - & + & - & + & - \\
\hline M. genitalium & - & - & - & - & - & - & - & - & - & - & - & $\mathrm{n} / \mathrm{a}$ & $\mathrm{n} / \mathrm{a}$ & - & - & - & - & - & - \\
\hline T. vaginalis & - & - & - & - & - & - & - & - & - & + & - & $\mathrm{n} / \mathrm{a}$ & $\mathrm{n} / \mathrm{a}$ & + & + & + & + & - & + \\
\hline
\end{tabular}

Each column across the categories reflects one individual participant.

+, Detected; - not detected; n/a, insufficient sample for qPCR; GC, N. gonorrhoeae; CT, C. trachomatis.

157,006 paired-end reads were obtained. After demultiplexing and elimination of low-quality reads, 100,216 reads were retained for downstream analyses of alpha diversity and beta diversity (mean number of reads per sample $=5,274$; range $=2,470-$ 9,528 reads). Paired reads were deposited in the Sequence Read Archive (SRA) under the accession PRJNA768436. The individual microbial communities of $N$. gonorrhoeae-infected patients were compared to those who presented with and without symptoms. Because other STI pathogens might be associated with different microbial community profiles, we also compared specimens from individuals without co-infecting C. trachomatis or T. vaginalis (by clinical test and/or real-time PCR) separately from those with coinfection. We first examined whether the relative abundance of Neisseria spp. assigned reads was associated with symptomatic presentation. Neisseria-assigned reads made up only $0.24 \%$ of all reads in the dataset and were a minor component of the bacterial community in each individual (Figure 1). In this limited set of specimens, the point estimate of the relative of abundance of reads from Neisseria spp. was highest in symptomatic individuals without C. trachomatis or T. vaginalis co-infection, though no significant difference in relative abundance between any group was observed (Figure 1).

\section{Microbial Community Diversity Is Different Between Symptomatic and Asymptomatic Neisseria gonorrhoeae Infection}

The overall alpha diversity did not differ when observed taxa, Chaol, and phylogenetic diversity were compared between individuals with symptomatic and asymptomatic N. gonorrhoeae infection (Figure 2A and Supplementary Figures S1A-C) and between individuals with and without other STI (Figure 2B and Supplementary Figures S1D,E). However, the number of dominant taxa comprising the majority of the microbial community (i.e., $90 \%$ of all detected taxa) was significantly lower in individuals with asymptomatic $N$. gonorrhoeae infection without STI co-infection vs. both individuals with symptomatic $N$. gonorrhoeae and with STI co-infection (Figure 2C).

Differences between symptomatic and asymptomatic patients, but not between patients with and without $C$. trachomatis and/or T. vaginalis co-infection, were reflected in beta diversity analyses, with statistically significant ANOSIM tests and clear separation on PCoA plots by two different methods: weighted Unifrac (ANOSIM $R=0.20, p$-value $=0.032$, Figure 3A) and unweighted Unifrac (ANOSIM $R=0.24, p$-value $=0.011$, Figure 3B).

\section{Asymptomatic Patients Without an STI Co-infection Are More Frequently Characterized by Low-Diversity, Lactobacillus-Dominant Genital Communities}

The relative abundance of Lactobacillus spp. assigned reads differed by patient group. The distribution of Lactobacillus spp.

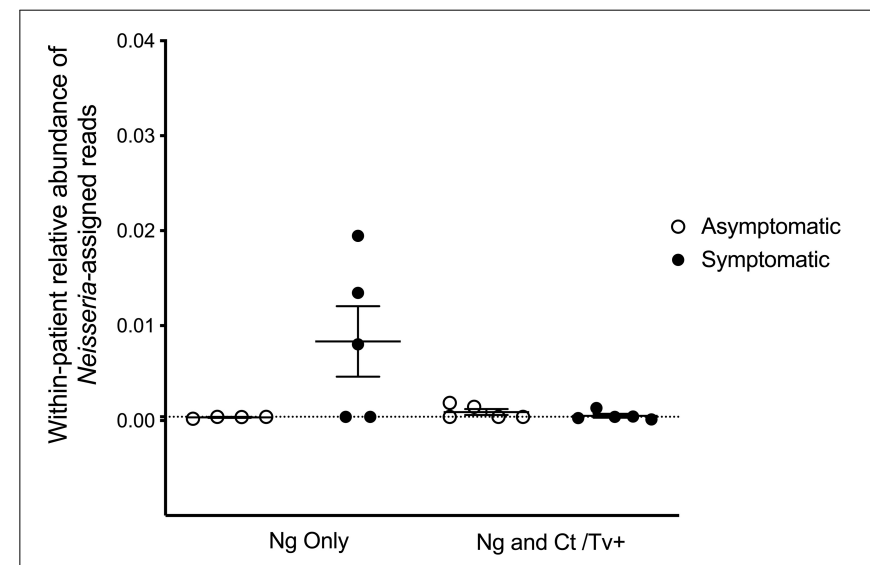

FIGURE 1 | Reads assigned to the Neisseria genus comprise a small proportion of the cervicovaginal microbial community. We characterized the genital microbial communities of 19 females with clinically confirmed gonorrhea using $16 \mathrm{~S}$ amplicon deep sequencing and microbiome analysis with QIIME. After demultiplexing and eliminating low-quality reads, 100,216 reads were retained for downstream analyses (mean number of reads per sample $=5,274$; range $=2,470-9,528$ reads). Neisseria-assigned $16 \mathrm{~S}$ ribosomal RNA gene reads made up only $0.24 \%$ of all reads in the dataset and are plotted for each individual's microbial community. No significant differences in relative abundance of $16 \mathrm{~S}$ reads from Neisseria spp. between any group was observed using one-way ANOVA with Tukey's correction for multiple comparisons. 


\section{A Alpha diversity by presence of reported symptoms}

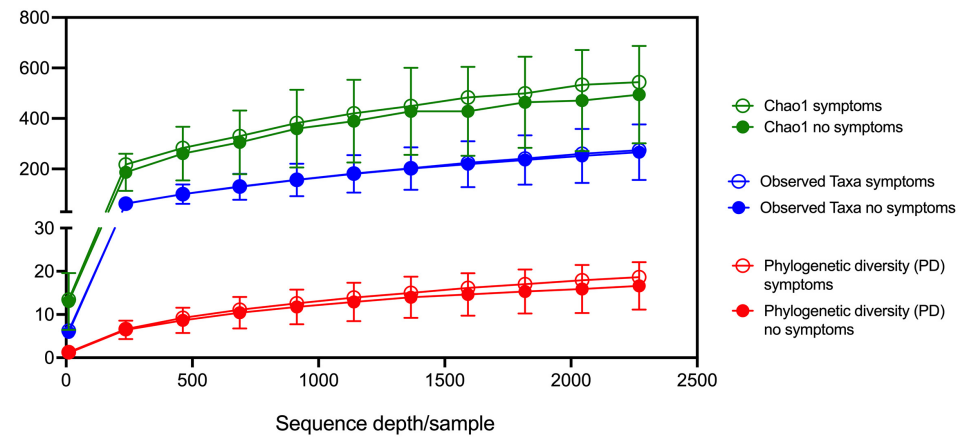

B Alpha diversity by C. trachomatis or T. vaginalis co-infection

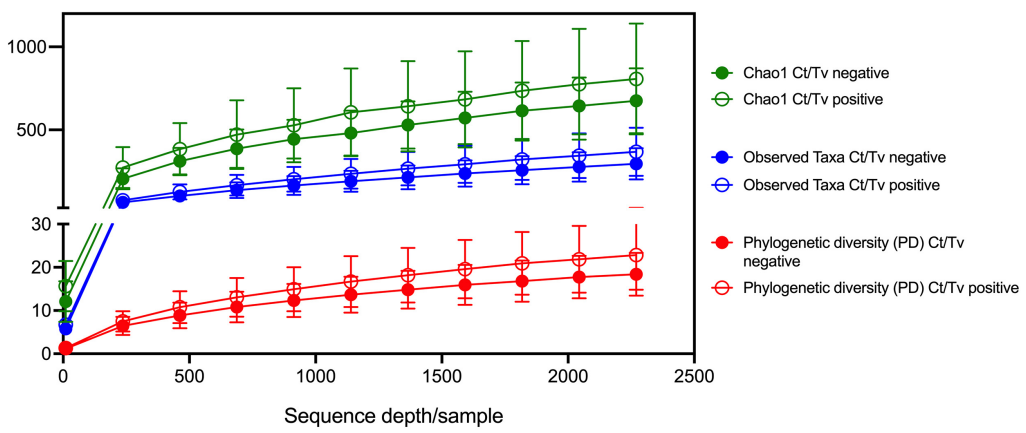

C

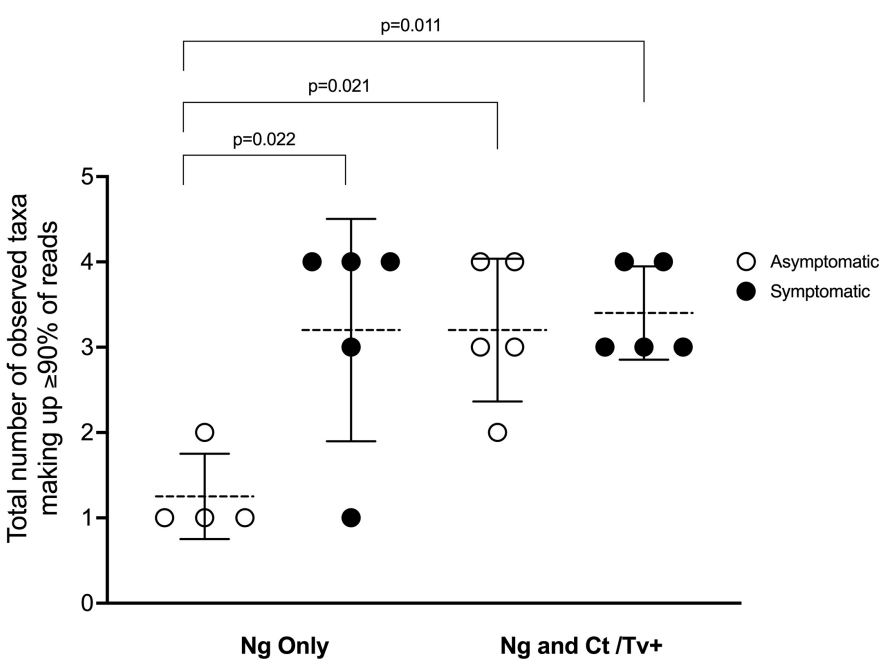

FIGURE 2 | Alpha diversity analyses with respect to clinical presentation and other STI co-infection. Alpha diversity was measured by three different metrics (Chao1; observed species; and PD, phylogenetic diversity) at a depth of 2,270 reads and visualized as rarefaction plots. Overall alpha diversity are plotted for the symptomatic and asymptomatic N. gonorrhoeae infection patient groups (A) and for the co-infection patient groups (i.e. with and without other STI) (B). The number of dominant taxa comprising the majority of the microbial community (i.e., $90 \%$ of all detected taxa) is plotted for individuals with asymptomatic and symptomatic N. gonorrhoeae infection with and without STI co-infection (C). Statistically significant differences between patient groups were explored with one way ANOVA with Tukey's correction for multiple comparisons.

relative abundances was as follows: $92.2 \%$ among asymptomatic individuals with no co-infection, $35.3 \%$ among asymptomatic individuals with co-infection, $21.6 \%$ among symptomatic individuals with no co-infection, and $11.5 \%$ among symptomatic individuals with co-infection (Figure 4A). This was evident when inspecting the individual taxa plots (Figure 4B), as the 


\section{A Weighted Unifrac}

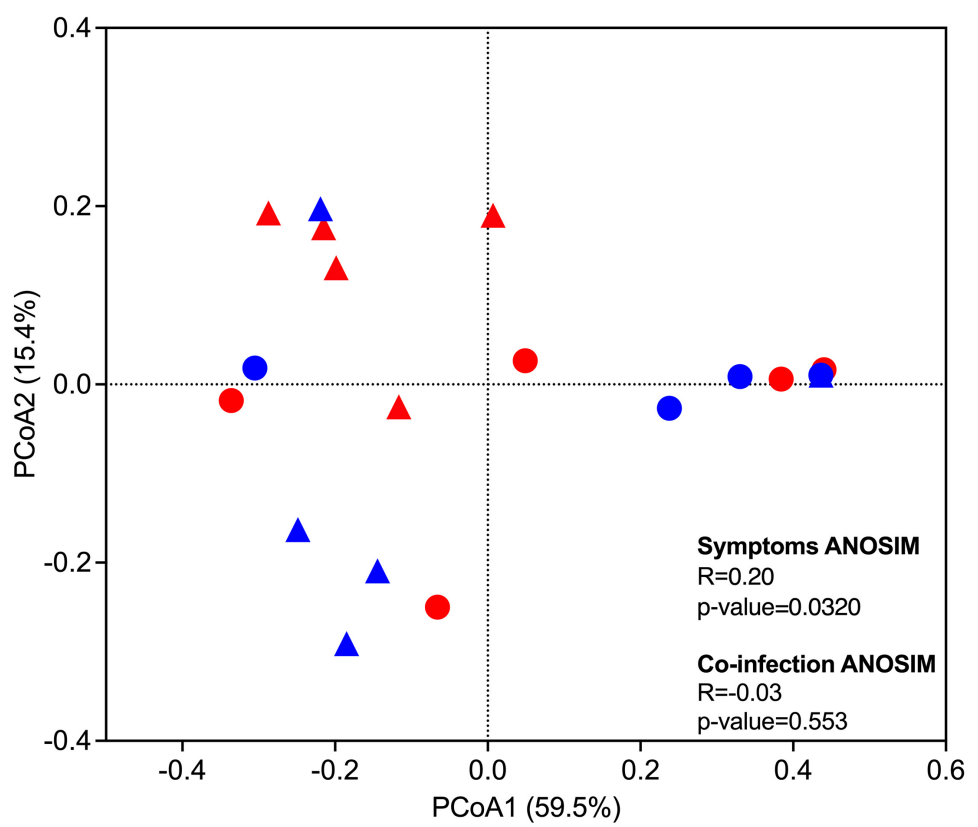

B Unweighted Unifrac

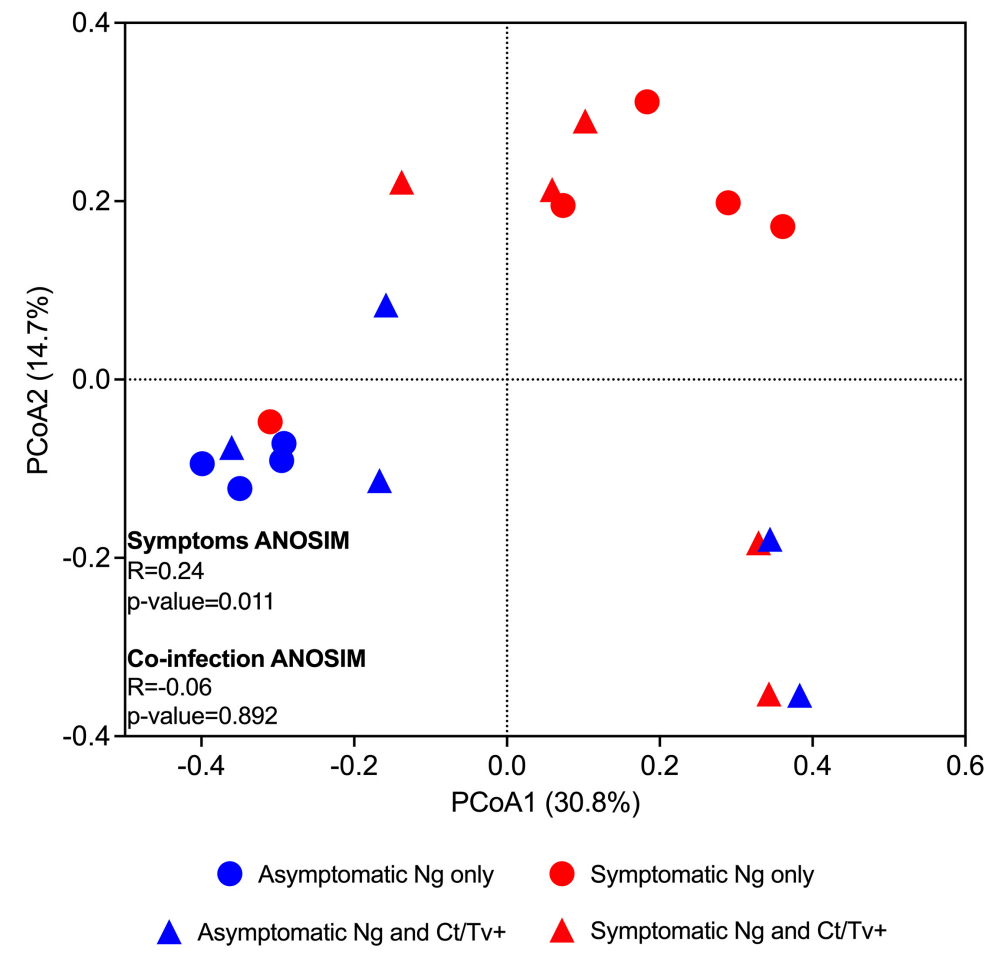

FIGURE 3 | Beta diversity analyses with respect to clinical presentation and other STI co-infection. Beta diversity estimates were calculated within QIIME using weighted (A) and unweighted Unifrac (B) distances between samples. Results were summarized and visualized through principal coordinate analysis (PCoA) in QIIME. ANOSIM tests were used to assess the strength of the clustering patterns and statistical significance. Differences between symptomatic and asymptomatic patients, but not between patients with and without $C$. trachomatis and/or T. vaginalis co-infection, were found, with clear separation on PCoA plots by two different methods: weighted Unifrac (ANOSIM $R=0.20, p$-value $=0.032$, A) and unweighted Unifrac (ANOSIM $R=0.24, p$-value $=0.011$ ). 
four asymptomatic patients with only $N$. gonorrhoeae infection and no detected co-infection were dominated by Lactobacillus taxa, whereas Lactobacillus-predominance was observed less frequently in specimens from women with symptomatic $N$. gonorrhoeae infection regardless of the presence of additional STI $(2 / 10,20.0 \%$ symptomatics vs. $6 / 9,66.7 \%$ asymptomatics, $p=0.040$, Figure 4A). Differences in within-patient relative abundance of Lactobacillus spp. in symptomatics with gonorrhea only vs. asymptomatics with gonorrhea were statistically significant ( $p=0.019$, Figure 5A). Similarly, the within-patient relative abundance of Lactobacillus spp. in symptomatics with gonorrhea only vs. that of symptomatic with co-infections also varied significantly ( $p=0.007$, Figure 5A).

Using BLAST and MUltiple Sequence Comparison by Log Expectation (MUSCLE) (Edgar, 2004), we investigated the 16S sequences of each taxa that was assigned Lactobacillus taxonomy and identified $L$. iners as the likeliest species (Supplementary Table 1). This led us to define Lactobacillus-dominant samples ( $n=8)$ as community-type 3 (CT3), using standard definitions of vaginal microbial structure (Ravel et al., 2011; Anahtar et al., 2015; Gosmann et al., 2017; Figure 4B).

The presence of specific Lactobacillus species was further assessed by presence/absence real-time PCR (Figure 5B). The Lactobacillus species most commonly detected among all women were L. iners, L. crispatus, L. jensenii, and L. gasseri (Figure 5B). In line with our microbiome analyses and BLAST homology searches, all asymptomatic women were positive for $L$. iners, and in 85 and $75 \%$ of symptomatic women with and without co-infection, respectively. Although L. crispatus was not the predominant Lactobacillus species in any of the specimens using $16 \mathrm{~S}$ sequencing, L. crispatus was detected by real-time PCR only in N. gonorrhoeae-infected individuals with asymptomatic presentation (Figure 5B).

\section{Symptomatic Neisseria gonorrhoeae and STI Co-infection Are Associated With a Diverse Cervicovaginal Microbial Community Composed of Bacterial Vaginosis-Associated Bacteria}

Having established that 8 of 19 samples (42.1\%) were L. inersdominated (CT3) and more commonly associated with asymptomatic $N$. gonorrhoeae infection, we investigated in more detail the remaining 11 samples, which were dominated by a diverse group of non-lactobacilli (Prevotella, a Lachnospiraceae genus, Sneathia, or Mycoplasma). We used BLAST and MUSCLE alignments to further characterize the composition of the non-Lactobacillus communities dominated by Lachnospiraceae and Mycoplasma. By applying BLAST on representative reads assigned to each genus of interest, we found that the likeliest species for Lachnospiraceae and Mycoplasma OTUs were Bacterial Vaginosis-Associated Bacterium-1 (BVAB1)/“Candidatus Lachnocurva vaginae" and M. hominis, respectively (Supplementary Table 1). Samples dominated by Prevotella $(n=6)$, Sneathia $(n=1)$, BVAB1 $(n=3)$, and M. hominis $(n=1)$ were classified as CT4/molecular BV. The Mycoplasma-dominant sample was included in the CT4 and molecular BV classifications. The CT4/molecular BV samples were more frequently found in symptomatic patients $(8 / 10,80 \%$ of symptomatics vs. $3 / 9,33.3 \%$ of asymptomatics, $p=0.040$ ) (Figure 4B). Among STI co-infected individuals, 7/10 (70.0\%) carried CT4 microbial communities compared to patients without co-infections $(4 / 9,44.4 \%)$, though this difference did not attain statistical significance $(p=0.255)$.

The prevalence of common $\mathrm{BV}$-associated bacteria was also assessed by commercially available microbial DNA real-time PCR assay (Figure 6). Of the BV-associated species included in the panel, Gardnerella vaginalis was present in all samples. Other species commonly associated with BV, like Atopobium vaginae, certain Prevotella spp., and Sneathia sanguinegens were also highly prevalent among this cohort of women, regardless of symptoms or STI co-infection status. Asymptomatic women infected only with $N$. gonorrhoeae $(n=4)$ carried the following species less frequently than symptomatic women infected only with $N$. gonorrhoeae $(n=5)$ : M. hominis $(25 \%$ vs. $80 \%)$, Prevotella buccalis (25\% vs. $80 \%)$, and Ureaplasma urealyticum ( $0 \%$ vs. 100\%). Similarly, asymptomatic females without co-infections also carried BV-associated bacteria less frequently when compared to those with symptoms or STI coinfections (Figure 6).

\section{DISCUSSION}

A large body of evidence links vaginal dysbiosis, such as clinical BV, to the risk of acquisition of several STIs, including gonorrhea (Martin et al., 1999; Atashili et al., 2008; Brotman, 2011; Bautista et al., 2017; Tamarelle et al., 2019). Despite the clear association between BV and STI acquisition risk, treatment of asymptomatic BV has not been found to reduce the incidence of $N$. gonorrhoeae or C. trachomatis infection incidence, raising the question whether a suboptimal vaginal environment is a modifiable biological cause of gonorrhea risk (Schwebke et al., 2016). However, Lactobacillus-based live probiotic therapy of vaginal dysbiosis has been recently shown to reduce not only BV (Aroutcheva et al., 2001; Witkin and Linhares, 2017), but also bacterial STI incidence (van de Wijgert and Verwijs, 2020). To the best of our knowledge, this report is the first to examine the association between the cervicovaginal microbiota composition and symptomatic $N$. gonorrhoeae infections in women. Using $16 \mathrm{~S}$ ribosomal RNA gene deep sequencing approaches on patient samples confirmed to be infected with $N$. gonorrhoeae by Aptima clinical testing, we show that the cervicovaginal microbiome is predictive of gonorrhea clinical presentation in women attending an STI clinic in the United States. These findings were confirmed by real-time polymerase chain reaction assays specific for several Lactobacillus species and BV-associated bacteria deployed in parallel on the same clinical samples.

Specimens collected from asymptomatic individuals with $N$. gonorrhoeae infection and no co-infection with Chlamydia trachomatis and/or Trichomonas vaginalis carried Lactobacillusdominant microbial communities more frequently than symptomatic patients without co-infection. Notably, this 
A

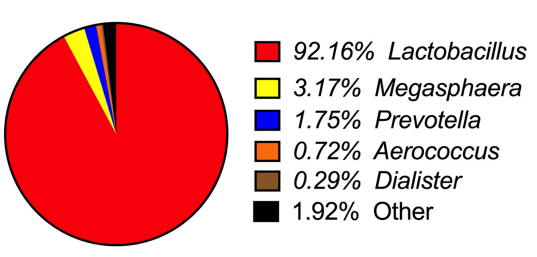

Asymptomatic, N. gonorrhoeae and C. trachomatis and/or $T$. vaginalis

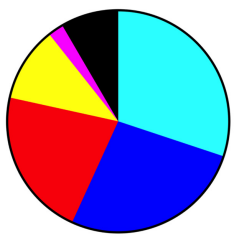

$30.11 \%$ Lachnospiraceae

$26.71 \%$ Prevotella

$21.62 \%$ Lactobacillus

$10.90 \%$ Megasphaera

$\square 2.25 \%$ Rs-045

$8.41 \%$ Other

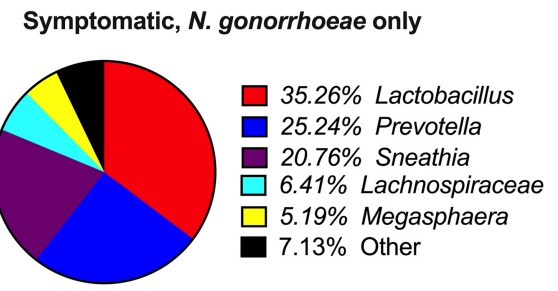

Symptomatic, $N$. gonorrhoeae and C. trachomatis and/or $T$. vaginalis

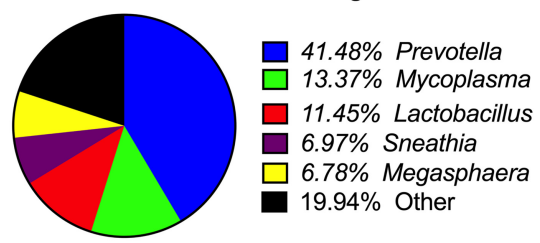

B

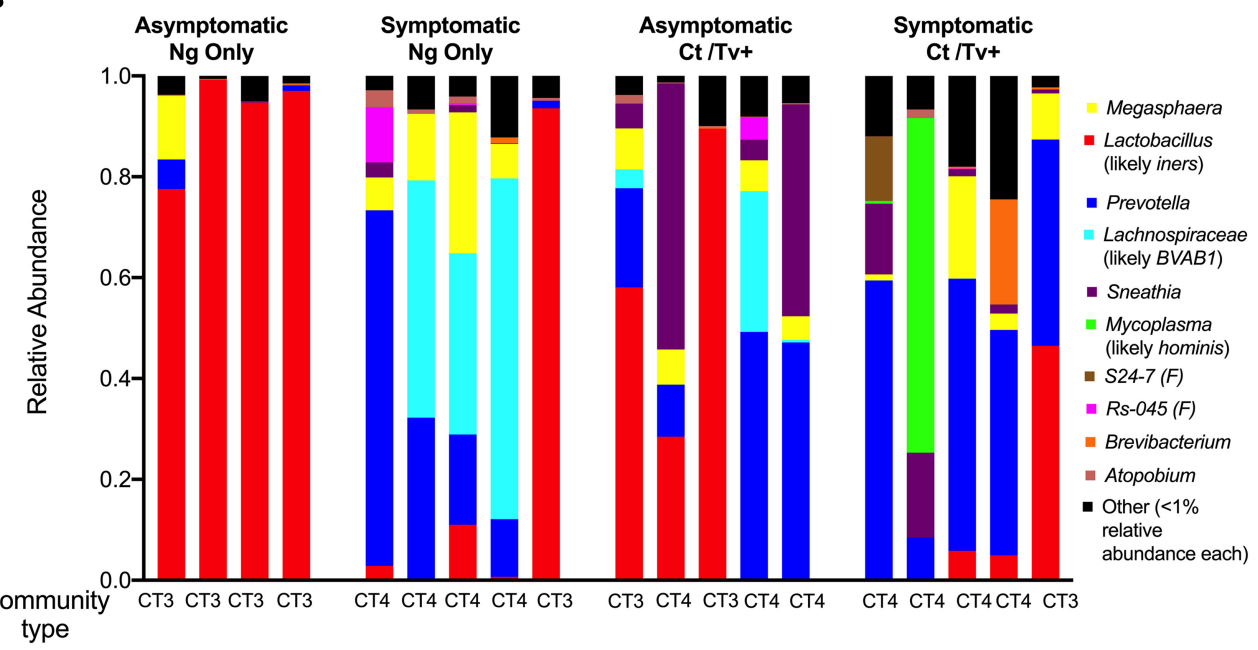

FIGURE 4 | Community composition of symptomatic and asymptomatic individuals with and without C. trachomatis and/or T. vaginalis co-infection. The mean relative abundances of the top five most prevalent bacterial genera identified within each patient group of interest are plotted as pie charts with each pie representing a group of interest (A). The relative abundances of the top ten taxa (genera- or family-level taxa, as applicable) identified across all 16S rRNA sequencing reads in the dataset are shown for each of the 19 participants included in the study. These top 10 taxa comprised $\nmid 99 \%$ of all reads in the entire dataset. We used BLAST and MUSCLE alignments to determine the likely species of communities dominated by Lactobacillus, Lachnospiraceae, and Mycoplasma and found them to be L. iners, Bacterial Vaginosis-Associated Bacterium-1 (BVAB1)/“Candidatus Lachnocurva vaginae," and M. hominis, respectively. The microbial community type (CT) designated for each participant, using standard definitions in the field, is provided (B).

Lactobacillus dominance was due to L. iners, and these microbiotas were classified as community type 3 (CT3), according to established definitions in the field (Ravel et al., 2011; Anahtar et al., 2015; Gosmann et al., 2017). Previous studies have established that $L$. iners-dominated vaginal microbiotas compared to L. crispatus-dominated vaginal microbiotas may place patients more at risk of STI infection, like chlamydia or HIV (Gosmann et al., 2017; van der Veer et al., 2017; Tamarelle et al., 2019). Interestingly, none of the females in our study had cervicovaginal microbiomes dominated by L. crispatus, which may be consistent with a protective effect by L. crispatus on STI infection risk. This is supported by in vitro studies with clinically isolated and lab strains of L. crispatus have been shown to inhibit the growth of $N$. gonorrhoeae in vitro (Vielfort et al., 2008), possibly through the effects of lactic acid acidification of the growth environment (Graver and Wade, 2011). While L. crispatus produces both isomers of lactic acid, L. iners and human cells only make $1(+)$ lactic acid (Spurbeck and Arvidson, 2010; Tachedjian et al., 2017). Accumulating evidence also suggests that $\mathrm{d}(-)$ lactic acid may impart greater protection 
A

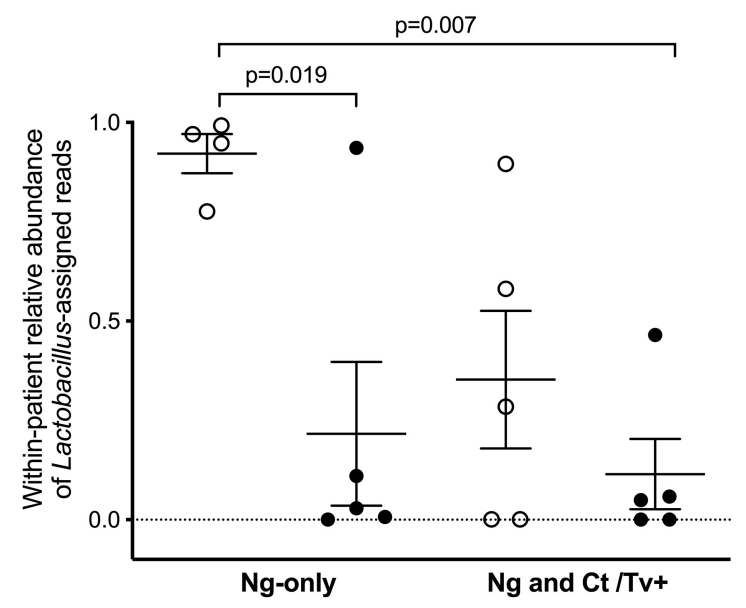

○ Asymptomatic

- Symptomatic

Ng-only

$\mathrm{Ng}$ and $\mathrm{Ct} / \mathrm{Tv}+$

B

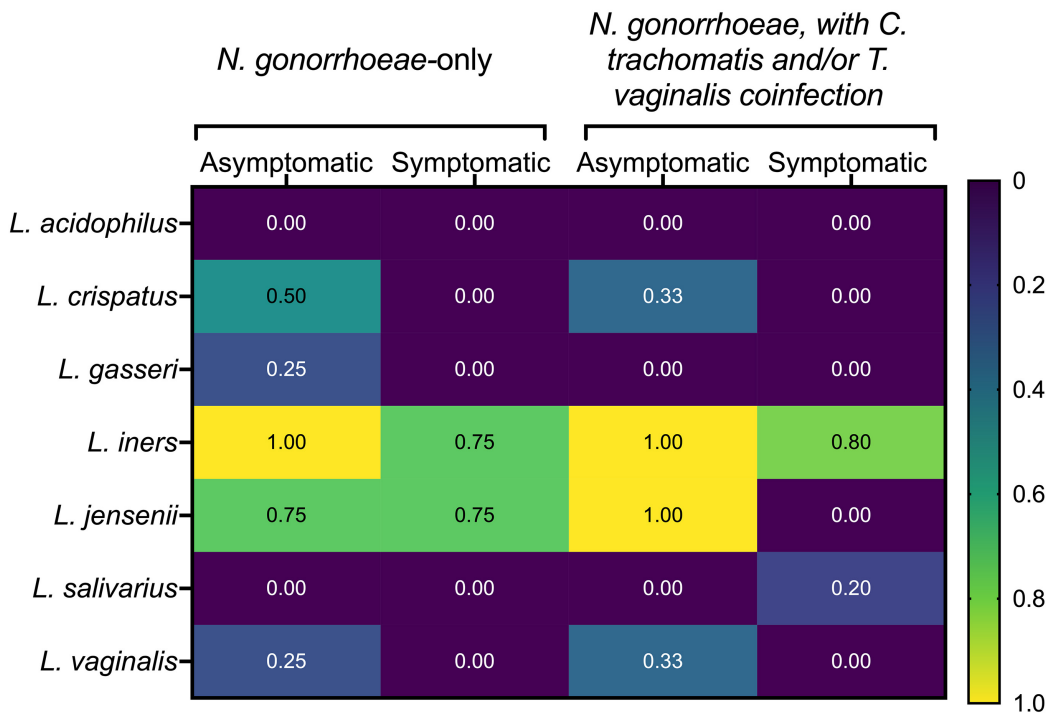

FIGURE 5 | Lactobacillus spp. detection with respect to clinical presentation and other STI co-infection. The fraction of reads assigned to Lactobacillus among all sequence reads comprising an individual's microbial community is shown (A). Participants have been grouped by symptom and co-infection status. Statistically significant differences between patient groups were explored with one-way ANOVA with Tukey's correction for multiple comparisons. The presence of specific Lactobacillus spp. was also assessed by the presence/absence of commercially available real-time PCR assay (B). Participants have been grouped by symptom and co-infection status. The fraction of individuals within each group positive for each of the seven Lactobacillus species in our panel (L. acidophilus, $L$. crispatus, $L$. gasseri, L. iners, L. jensenii, L. salivarius, and L. vaginalis) are shown as a heatmap, with values ranging from "O" (i.e., none of the women in the group positive for that species) to "1.0" (i.e., all women in the group positive for that species).

against STI pathogens than $1(+)$ lactic acid potentially via effects on human host cells rather than pathogen cells (Nunn et al., 2015; Edwards et al., 2019). In humans, L. crispatus-dominant vaginal microbiota is associated with reduced risk of acquisition of other STI, like HIV (Borgdorff et al., 2014; Gosmann et al., 2017; van der Veer et al., 2017; Tamarelle et al., 2019).

Neisseria gonorrhoeae-infected patients who reported symptoms were found to have genital microbiomes composed of a mixture of various bacterial anaerobes, such as Prevotella, Sneathia, Mycoplasma hominis, and BVAB1/“Candidatus
Lachnocurva vaginae" (Holm et al., 2020). These women with genital microbiomes composed of anaerobes were deemed to have molecular BV, as defined by established classifications in the field based on diversity and relative abundance of bacterial taxa (Ravel et al., 2011; Anahtar et al., 2015; Gosmann et al., 2017). This included the Mycoplasma-dominant sample because of three main reasons that definitions of molecular BV take into account: like Prevotella and Sneathia, it can overgrow in cases of BV (Fredricks et al., 2005; Onderdonk et al., 2016), its prevalence in $\mathrm{BV}$ patients is three times higher compared to healthy women 


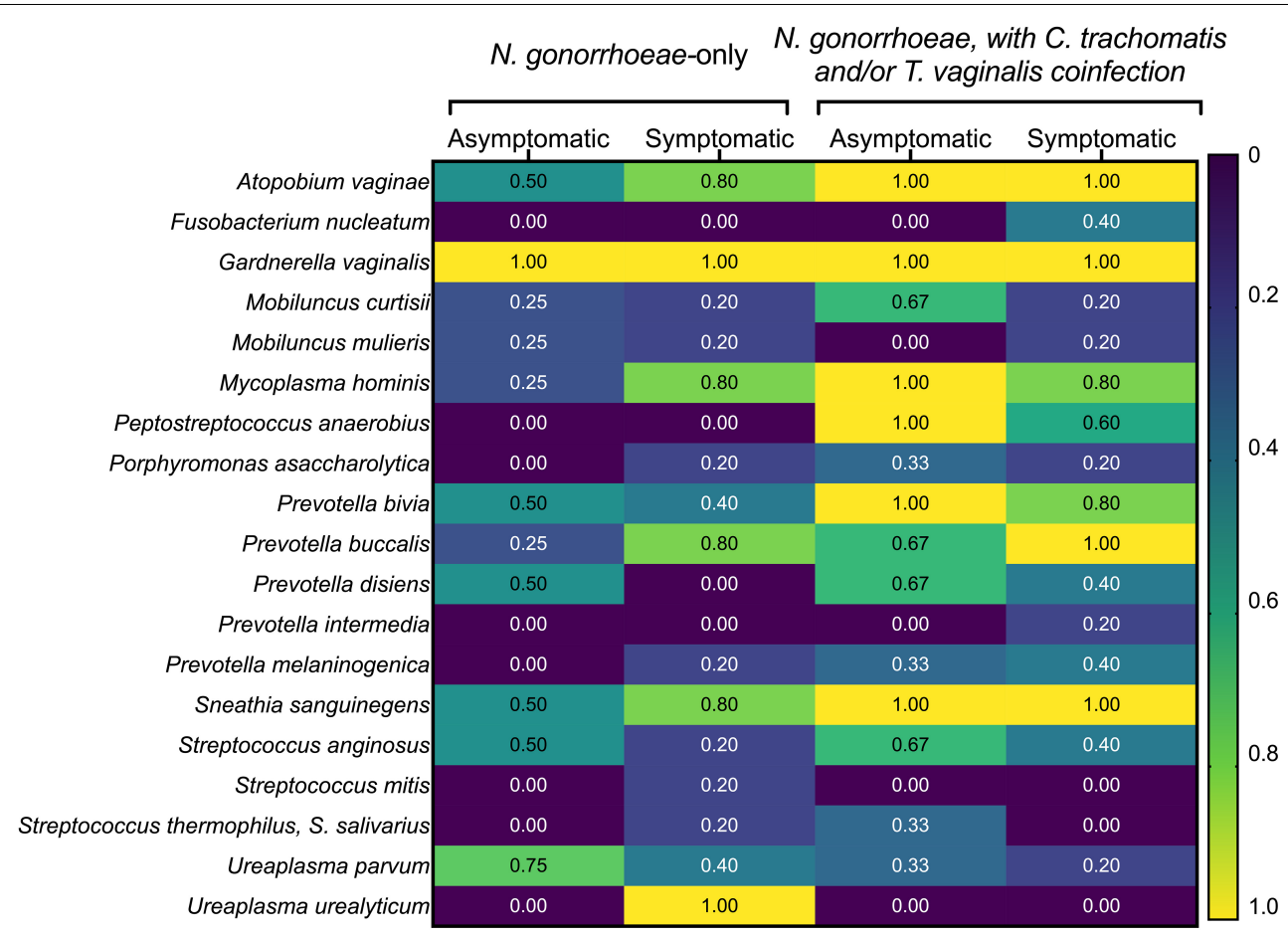

FIGURE 6 | Prevalence of common bacterial vaginosis-associated bacteria detected with commercially available microbial DNA real-time PCR assay. The presence of the indicated BV-associated bacterial species was assessed by the presence/absence of commercially available real-time PCR assay. Participants have been grouped by symptom and co-infection status. The fraction of individuals within each group positive for each of the seven BV-associated bacteria in the panel are shown as a heatmap, with values ranging from "0" (i.e., none of the women in the group positive for that species) to "1.0" (i.e., all women in the group positive for that species).

(Rumyantseva et al., 2019) and it is associated with severe genital mucosal inflammation (Martin et al., 2013).

A possible explanation for the association of symptoms in $N$. gonorrhoeae infection and $\mathrm{BV}$-associated microbial communities relates to the known increase of inflammation and inflammatory mediators in women with BV. Several studies have shown that females with clinical BV or low Lactobacillus abundance and high diversity of anaerobes also harbor higher concentrations of pro-inflammatory cytokines in their genital tract (Anahtar et al., 2015) and higher levels of the proinflammatory cytokines (IL-1 $\alpha$, IL-1 $\beta$, IL-6, IL-12, and IL-8) when compared to BV-negative women (Kyongo et al., 2015). Furthermore, symptoms of abnormal vaginal discharge were also found to associate with elevated levels of IL-1 $\beta$, IP-10, IL-8, and GCSF, linking inflammatory cytokines to vaginal symptoms, particularly vaginal discharge (Kyongo et al., 2015). Notably, the more the vaginal microbiota shifts toward dysbiosis, the more marked the inflammation (Cohen et al., 2010; Anahtar et al., 2015; Lennard et al., 2018), independently of concurrent STIs, including HIV and gonorrhea (Anahtar et al., 2015).

We recognize that our study had limitations. Because of the nature of the study design, we had no information on whether our symptomatic subjects also had clinically defined $\mathrm{BV}$. However, the association between BV-associated microbes and cervicovaginal community type suggests that further studies of the association of $\mathrm{BV}$ with symptomatic $N$. gonorrhoeae infection are needed. Because we lacked specimens from $N$. gonorrhoeae-negative women, our study was limited to analyses among $N$. gonorrhoeae-positive women. Thus, despite a strong association between low-Lactobacillus vaginal communities (molecular BV) and risk of acquisition of STIs like HIV and chlamydia (Borgdorff et al., 2014; Gosmann et al., 2017; van der Veer et al., 2017), as well as a strong association between clinical BV and risk of N. gonorrhoeae infection (Brotman, 2011; Gallo et al., 2012; Bautista et al., 2017), our study could not examine whether the vaginal microbiota composition associates in characteristic ways with risk or protection from $N$. gonorrhoeae infection. Instead, we focused on characterizing the relationship between vaginal communities and clinical presentation among women with clinically diagnosed $N$. gonorrhoeae infection. Future prospective studies are needed to determine the protective effect of Lactobacillus-dominated vaginal composition against $N$. gonorrhoeae infection. Finally, the majority of our study participants identified as African American. Previous BV prevalence studies reported that compared to Caucasian women, low-Lactobacillus vaginal microbiotas are more common in African American and Latin women (Zhou et al., 2007; Ravel et al., 2011; Fettweis et al., 2014) and that up to 50\% of African American women may harbor vaginal microbiotas deplete in Lactobacillus species (Allsworth and Peipert, 2007). Future studies on how race, the vaginal microbiota, and N. gonorrhoeae risk intersect are needed. 
Overall, our study showed that symptomatic vs. asymptomatic gonorrhea presentation is correlated with having molecular BV, leading to two possible explanations. First, that the molecular BV community type compared to the L. iners dominated community type may have predisposed to the development of gonococcal-associated symptoms. Second, that the BV state developed after or was even caused by the establishment of $N$. gonorrhoeae infection due to the promotion of the growth of BV-associated bacteria or a loss of Lactobacillus species. Thus, our findings suggest that the cervicovaginal microbiota is a determinant, or at least a contributor, to gonorrhea clinical presentation in women. Further studies defining the relationship between genital tract microbiomes and the proinflammatory immune responses in symptomatic presentation of $N$. gonorrhoeae infection are needed to elucidate whether Lactobacilli or BV-defining microbial communities serve as a biomarker for symptoms in N. gonorrhoeae infections or directly impact symptoms.

\section{DATA AVAILABILITY STATEMENT}

The datasets presented in this study (accession PRJNA768436) can be found at the link: https://www.ncbi.nlm.nih.gov/ bioproject/?term=\%20PRJNA768436.

\section{ETHICS STATEMENT}

The studies involving human-derived specimens were reviewed and approved by the University of North Carolina Institutional Review Board (Studies 11-0047 and 15-2531). The research was found to meet the criteria for a waiver of informed consent for research [45 CFR 46.116(d)] and waiver of HIPAA authorization [45 CFR 164.512(i)(2)(ii)] as the study entailed research on existing specimens, posing minimal risk to participants; the waiver did not adversely affect the rights or welfare of the participants, and consent/assent would have been impracticable given the loss to follow up.

\section{AUTHOR CONTRIBUTIONS}

All authors contributed to the writing and revision of the manuscript. AL wrote the first draft of the manuscript,

\section{REFERENCES}

Allsworth, J. E., and Peipert, J. F. (2007). Prevalence of bacterial vaginosis: 20012004 national health and nutrition examination survey data. Obstet. Gynecol. 109, 114-120. doi: 10.1097/01.AOG.0000247627.84791.91

Altschul, S. F., Gish, W., Miller, W., Myers, E. W., and Lipman, D. J. (1990). Basic local alignment search tool. J. Mol. Biol. 215, 403-410.

Amsel, R., Totten, P. A., Spiegel, C. A., Chen, K. C., Eschenbach, D., and Holmes, K. K. (1983). Nonspecific vaginitis. Diagnostic criteria and microbial and epidemiologic associations. Am. J. Med. 74, 14-22. doi: 10.1016/0002-9343(83) 91112-9

Anahtar, M. N., Byrne, E. H., Doherty, K. E., Bowman, B. A., Yamamoto, H. S., Soumillon, M., et al. (2015). Cervicovaginal bacteria are a major modulator of performed the lab investigation, and analyzed the data. JD conceptualized the study. JD and AW conducted formal analysis, methodology selection and experimental design, and supervision. AS oversaw clinical specimen collection. GS and AM contributed to experimental design and data analysis.

\section{FUNDING}

The project described was supported by the National Center for Advancing Translational Sciences, National Institutes of Health, through Grant Award Number TL1TR002491 supporting AW and through an NC TraCS Pilot Grant supported by Grant Award Number UL1TR002489 awarded to JD. Additionally, the project was supported by the National Institute of Allergy and Infectious Diseases, National Institutes of Health, through the UNC program for Training in Sexually Transmitted Infections and HIV (T32AI007001) supporting AL and by Grant Award Numbers U19AI113170 and AI144180 awarded to JD, AM, and GS. The Duke Regional Biocontainment Laboratory was partially constructed with funding from the NIH/NIAID (UC6AI058607; GS). The content is solely the responsibility of the authors and does not necessarily represent the official views of the NIH.

\section{ACKNOWLEDGMENTS}

We extend our sincere thanks to Adriane Osborne, WNP, and to the STI clinic staff and participants at the Durham County Public Health Department for making this study possible. We thank UNC Microbiome Core, and in particular Dr. M. Andrea Azcarate-Peril and Dr. Jeff Roach, for the excellent execution of the library preparation and sequencing, and subsequent analysis support.

\section{SUPPLEMENTARY MATERIAL}

The Supplementary Material for this article can be found online at: https://www.frontiersin.org/articles/10.3389/fmicb. 2021.790531/full\#supplementary-material

host inflammatory responses in the female genital tract. Immunity 42, 965-976. doi: 10.1016/j.immuni.2015.04.019

Aroutcheva, A., Gariti, D., Simon, M., Shott, S., Faro, J., Simoes, J. A., et al. (2001). Defense factors of vaginal lactobacilli. Am. J. Obstet. Gynecol. 185, 375-379. doi: $10.1067 / \mathrm{mob} .2001 .115867$

Atashili, J., Poole, C., Ndumbe, P. M., Adimora, A. A., and Smith, J. S. (2008). Bacterial vaginosis and HIV acquisition: a meta-analysis of published studies. AIDS 22, 1493-1501. doi: 10.1097/QAD.0b013e3283021a37

Bautista, C. T., Wurapa, E. K., Sateren, W. B., Morris, S. M., Hollingsworth, B. P., and Sanchez, J. L. (2017). Association of bacterial vaginosis with chlamydia and gonorrhea among women in the U.S. Army. Am. J. Prev. Med. 52, 632-639.

Borgdorff, H., Tsivtsivadze, E., Verhelst, R., Marzorati, M., Jurriaans, S., Ndayisaba, G. F., et al. (2014). Lactobacillus-dominated cervicovaginal microbiota 
associated with reduced HIV/STI prevalence and genital HIV viral load in African women. ISME J. 8, 1781-1793. doi: 10.1038/ismej.2014.26

Brotman, R. M. (2011). Vaginal microbiome and sexually transmitted infections: an epidemiologic perspective. J. Clin. Invest. 121, 4610-4617. doi: 10.1172/ JCI57172

Caporaso, J. G., Bittinger, K., Bushman, F. D., DeSantis, T. Z., Andersen, G. L., and Knight, R. (2010a). PyNAST: a flexible tool for aligning sequences to a template alignment. Bioinformatics 26, 266-267. doi: 10.1093/bioinformatics/btp636

Caporaso, J. G., Kuczynski, J., Stombaugh, J., Bittinger, K., Bushman, F. D., Costello, E. K., et al. (2010b). QIIME allows analysis of high-throughput community sequencing data. Nat. Methods 7, 335-336. doi: 10.1038/nmeth.f. 303

Cohen, C. R., Moscicki, A. B., Scott, M. E., Ma, Y., Shiboski, S., Bukusi, E., et al. (2010). Increased levels of immune activation in the genital tract of healthy young women from sub-Saharan Africa. AIDS 24, 2069-2074. doi: 10.1097/ QAD.0b013e32833c323b

Coleman, J. S., Hitti, J., Bukusi, E. A., Mwachari, C., Muliro, A., Nguti, R., et al. (2007). Infectious correlates of HIV-1 shedding in the female upper and lower genital tracts. AIDS 21, 755-759. doi: 10.1097/QAD.0b013e32801 $2 \mathrm{~b} 838$

DeSantis, T. Z., Hugenholtz, P., Larsen, N., Rojas, M., Brodie, E. L., Keller, K., et al. (2006). Greengenes, a chimera-checked 16S rRNA gene database and workbench compatible with ARB. Appl. Environ. Microbiol. 72, 5069-5072. doi: 10.1128/AEM.03006-05

Edgar, R. C. (2004). MUSCLE: multiple sequence alignment with high accuracy and high throughput. Nucleic Acids Res. 32, 1792-1797. doi: 10.1093/nar/gkh340

Edgar, R. C. (2010). Search and clustering orders of magnitude faster than BLAST. Bioinformatics 26, 2460-2461. doi: 10.1093/bioinformatics/btq461

Edwards, V. L., Smith, S. B., McComb, E. J., Tamarelle, J., Ma, B., Humphrys, M. S., et al. (2019). The cervicovaginal microbiota-host interaction modulates chlamydia trachomatis infection. mBio 10:e01548-19.

Elovitz, M. A., Gajer, P., Riis, V., Brown, A. G., Humphrys, M. S., Holm, J. B., et al. (2019). Cervicovaginal microbiota and local immune response modulate the risk of spontaneous preterm delivery. Nat. Commun. 10:1305. doi: 10.1038/ s41467-019-09285-9

FastQC (2015). FastQC: A Quality Control Tool for High Throughput Sequence Data [Online]. Available online at: https://qubeshub.org/resources/fastqc (accessed November 10, 2019).

Fettweis, J. M., Brooks, J. P., Serrano, M. G., Sheth, N. U., Girerd, P. H., Edwards, D. J., et al. (2014). Differences in vaginal microbiome in African American women versus women of European ancestry. Microbiology (Reading) 160, 2272-2282. doi: 10.1099/mic.0.081034-0

Fettweis, J. M., Serrano, M. G., Brooks, J. P., Edwards, D. J., Girerd, P. H., Parikh, H. I., et al. (2019). The vaginal microbiome and preterm birth. Nat. Med. 25, 1012-1021.

Fredricks, D. N., Fiedler, T. L., and Marrazzo, J. M. (2005). Molecular identification of bacteria associated with bacterial vaginosis. N. Engl. J. Med. 353, 1899-1911. doi: 10.1056/NEJMoa043802

Gallo, M. F., Macaluso, M., Warner, L., Fleenor, M. E., Hook, E. W. III, Brill, I., et al. (2012). Bacterial vaginosis, gonorrhea, and chlamydial infection among women attending a sexually transmitted disease clinic: a longitudinal analysis of possible causal links. Ann. Epidemiol. 22, 213-220. doi: 10.1016/j.annepidem. 2011.11.005

Gosmann, C., Anahtar, M. N., Handley, S. A., Farcasanu, M., Abu-Ali, G., Bowman, B. A., et al. (2017). Lactobacillus-deficient cervicovaginal bacterial communities are associated with increased HIV acquisition in young South African women. Immunity 46, 29-37. doi: 10.1016/j.immuni.2016.12.013

Graver, M. A., and Wade, J. J. (2011). The role of acidification in the inhibition of Neisseria gonorrhoeae by vaginal lactobacilli during anaerobic growth. Ann. Clin. Microbiol. Antimicrob. 10:8. doi: 10.1186/1476-0711-10-8

Haas, B. J., Gevers, D., Earl, A. M., Feldgarden, M., Ward, D. V., Giannoukos, G., et al. (2011). Chimeric $16 \mathrm{~S}$ rRNA sequence formation and detection in Sanger and 454-pyrosequenced PCR amplicons. Genome Res. 21, 494-504. doi: $10.1101 /$ gr.112730.110

Handsfield, H. H., Lipman, T. O., Harnisch, J. P., Tronca, E., and Holmes, K. K. (1974). Asymptomatic gonorrhea in men. Diagnosis, natural course, prevalence and significance. N. Engl. J. Med. 290, 117-123. doi: 10.1056/ NEJM197401172900301
Hazel, A., Marino, S., and Simon, C. (2015). An anthropologically based model of the impact of asymptomatic cases on the spread of Neisseria gonorrhoeae. J. $R$. Soc. Interface 12:20150067. doi: 10.1098/rsif.2015.0067

Hazel, A., Ponnaluri-Wears, S., Davis, G. S., Low, B. S., and Foxman, B. (2014). High prevalence of Neisseria gonorrhoeae in a remote, undertreated population of Namibian pastoralists. Epidemiol. Infect. 142, 2422-2432. doi: 10.1017/ S0950268813003488

Holm, J. B., France, M. T., Ma, B., McComb, E., Robinson, C. K., Mehta, A., et al. (2020). Comparative metagenome-assembled genome analysis of "Candidatus Lachnocurva vaginae", formerly known as bacterial vaginosisassociated bacterium-1 (BVAB1). Front. Cell Infect. Microbiol. 10:117. doi: 10. 3389/fcimb.2020.00117

Hologic (2016). Aptima Combo $2^{\circledR}$ Assay for Ng/Ct Clinical Testing [Package Insert]. San Diego, CA: Hologic.

Joag, V., Obila, O., Gajer, P., Scott, M. C., Dizzell, S., Humphrys, M., et al. (2019). Impact of standard bacterial vaginosis treatment on the genital microbiota, immune milieu, and ex vivo human immunodeficiency virus susceptibility. Clin. Infect. Dis. 68, 1675-1683. doi: 10.1093/cid/ciy762

Kent, C. K., Chaw, J. K., Wong, W., Liska, S., Gibson, S., Hubbard, G., et al. (2005). Prevalence of rectal, urethral, and pharyngeal chlamydia and gonorrhea detected in 2 clinical settings among men who have sex with men: San Francisco, California, 2003. Clin. Infect. Dis. 41, 67-74. doi: 10.1086/430704

Kyongo, J. K., Crucitti, T., Menten, J., Hardy, L., Cools, P., Michiels, J., et al. (2015). Cross-sectional analysis of selected genital tract immunological markers and molecular vaginal microbiota in sub-Saharan African Women, with relevance to HIV risk and prevention. Clin. Vaccine Immunol. 22, 526-538. doi: 10.1128/ CVI.00762-14

Lennard, K., Dabee, S., Barnabas, S. L., Havyarimana, E., Blakney, A., Jaumdally, S. Z., et al. (2018). Microbial composition predicts genital tract inflammation and persistent bacterial vaginosis in South African adolescent females. Infect. Immun. 86:e00410-17.

Lovett, A., and Duncan, J. A. (2018). Human Immune responses and the natural history of Neisseria gonorrhoeae infection. Front. Immunol. 9:3187. doi: 10. 3389/fimmu.2018.03187

Lozupone, C., and Knight, R. (2005). UniFrac: a new phylogenetic method for comparing microbial communities. Appl. Environ. Microbiol. 71, 8228-8235. doi: 10.1128/AEM.71.12.8228-8235.2005

Martin, D. H., Zozaya, M., Lillis, R. A., Myers, L., Nsuami, M. J., and Ferris, M. J. (2013). Unique vaginal microbiota that includes an unknown mycoplasma-like organism is associated with Trichomonas vaginalis infection. J. Infect. Dis. 207, 1922-1931. doi: 10.1093/infdis/jit100

Martin, H. L., Richardson, B. A., Nyange, P. M., Lavreys, L., Hillier, S. L., Chohan, B., et al. (1999). Vaginal lactobacilli, microbial flora, and risk of human immunodeficiency virus type 1 and sexually transmitted disease acquisition. J. Infect. Dis. 180, 1863-1868. doi: 10.1086/315127

Martin-Sanchez, M., Ong, J. J., Fairley, C. K., Chen, M. Y., Williamson, D. A., Maddaford, K. J., et al. (2020). Clinical presentation of asymptomatic and symptomatic heterosexual men who tested positive for urethral gonorrhoea at a sexual health clinic in Melbourne, Australia. BMC Infect. Dis. 20:486. doi: 10.1186/s12879-020-05197-y

Masson, L., Mlisana, K., Little, F., Werner, L., Mkhize, N. N., Ronacher, K., et al. (2014). Defining genital tract cytokine signatures of sexually transmitted infections and bacterial vaginosis in women at high risk of HIV infection: a cross-sectional study. Sex Transm. Infect. 90, 580-587. doi: 10.1136/sextrans2014-051601

Masson, L., Passmore, J. A., Liebenberg, L. J., Werner, L., Baxter, C., Arnold, K. B., et al. (2015). Genital inflammation and the risk of HIV acquisition in women. Clin. Infect. Dis. 61, 260-269. doi: 10.1093/cid/civ298

McClelland, R. S., Lingappa, J. R., Srinivasan, S., Kinuthia, J., John-Stewart, G. C., Jaoko, W., et al. (2018). Evaluation of the association between the concentrations of key vaginal bacteria and the increased risk of HIV acquisition in African women from five cohorts: a nested case-control study. Lancet Infect. Dis. 18, 554-564. doi: 10.1016/S1473-3099(18)30058-6

McKinnon, L. R., Achilles, S. L., Bradshaw, C. S., Burgener, A., Crucitti, T., Fredricks, D. N., et al. (2019). The evolving facets of bacterial vaginosis: implications for HIV transmission. AIDS Res. Hum. Retroviruses 35, 219-228. doi: 10.1089/AID.2018.0304 
Nunn, K. L., Wang, Y. Y., Harit, D., Humphrys, M. S., Ma, B., Cone, R., et al. (2015). Enhanced trapping of HIV-1 by human cervicovaginal mucus is associated with Lactobacillus crispatus-dominant microbiota. mBio 6:e01084-15. doi: 10.1128/ mBio.01084-15

Onderdonk, A. B., Delaney, M. L., and Fichorova, R. N. (2016). The human microbiome during bacterial vaginosis. Clin. Microbiol. Rev. 29, 223-238. doi: 10.1128/CMR.00075-15

Ong, J. J., Fethers, K., Howden, B. P., Fairley, C. K., Chow, E. P. F., Williamson, D. A., et al. (2017). Asymptomatic and symptomatic urethral gonorrhoea in men who have sex with men attending a sexual health service. Clin. Microbiol. Infect. 23, 555-559. doi: 10.1016/j.cmi.2017.02.020

Peebles, K., Velloza, J., Balkus, J. E., McClelland, R. S., and Barnabas, R. V. (2019). High global burden and costs of bacterial vaginosis: a systematic review and meta-analysis. Sex Transm. Dis. 46, 304-311. doi: 10.1097/OLQ. 0000000000000972

Platt, R., Rice, P. A., and McCormack, W. M. (1983). Risk of acquiring gonorrhea and prevalence of abnormal adnexal findings among women recently exposed to gonorrhea. JAMA 250, 3205-3209.

Potterat, J. J., Dukes, R. L., and Rothenberg, R. B. (1987). Disease transmission by heterosexual men with gonorrhea: an empiric estimate. Sex Transm. Dis. 14, 107-110. doi: 10.1097/00007435-198704000-00010

Price, M. N., Dehal, P. S., and Arkin, A. P. (2010). FastTree 2-approximately maximum-likelihood trees for large alignments. PLoS One 5:e9490. doi: 10. 1371/journal.pone.0009490

Qiagen. (2021). Microbial DNA qPCR Arrays. Available online at: https:/www.qiagen.com/us/products/discovery-and-translational-research/ pcr-qpcr-dpcr/qpcr-assays-and-instruments/microbial-dna-qpcr-assays-andpanels/microbial-dna-qpcr-arrays/ (accessed November 29, 2021)

Ravel, J., Gajer, P., Abdo, Z., Schneider, G. M., Koenig, S. S., McCulle, S. L., et al. (2011). Vaginal microbiome of reproductive-age women. Proc. Natl. Acad. Sci. U.S.A. 108(Suppl. 1), 4680-4687.

Reekie, J., Donovan, B., Guy, R., Hocking, J. S., Kaldor, J. M., Mak, D., et al. (2019). Risk of ectopic pregnancy and tubal infertility following gonorrhea and chlamydia infections. Clin. Infect. Dis. 69, 1621-1623. doi: 10. 1093/cid/ciz145

Reekie, J., Donovan, B., Guy, R., Hocking, J. S., Kaldor, J. M., Mak, D. B., et al. (2018). Risk of pelvic inflammatory disease in relation to chlamydia and gonorrhea testing, repeat testing, and positivity: a population-based cohort study. Clin. Infect. Dis. 66, 437-443. doi: 10.1093/cid/cix769

Rognes, T., Flouri, T., Nichols, B., Quince, C., and Mahe, F. (2016). VSEARCH: a versatile open source tool for metagenomics. PeerJ 4:e2584. doi: 10.7717/peerj. 2584

Rowley, J., Vander Hoorn, S., Korenromp, E., Low, N., Unemo, M., Abu-Raddad, L. J., et al. (2019). Chlamydia, gonorrhoea, trichomoniasis and syphilis: global prevalence and incidence estimates, 2016. Bull. World Health Organ. 97, 548562. doi: 10.2471/BLT.18.228486

Rumyantseva, T., Khayrullina, G., Guschin, A., and Donders, G. (2019). Prevalence of Ureaplasma spp. and Mycoplasma hominis in healthy women and patients with flora alterations. Diagn. Microbiol. Infect. Dis. 93, 227-231. doi: 10.1016/j. diagmicrobio.2018.10.001

Sandstrom, E. G., Knapp, J. S., Reller, L. B., Thompson, S. E., Hook, E. W. III, and Holmes, K. K. (1984). Serogrouping of Neisseria gonorrhoeae: correlation of serogroup with disseminated gonococcal infection. Sex Transm. Dis. 11, 77-80. doi: 10.1097/00007435-198404000-00005

Schwebke, J. R., Lee, J. Y., Lensing, S., Philip, S. S., Wiesenfeld, H. C., Seña, A. C., et al. (2016). Home screening for bacterial vaginosis to prevent sexually transmitted diseases. Clin. Infect. Dis. 62, 531-536. doi: 10.1093/cid/civ975

Sha, B. E., Zariffard, M. R., Wang, Q. J., Chen, H. Y., Bremer, J., Cohen, M. H., et al. (2005). Female genital-tract HIV load correlates inversely with Lactobacillus species but positively with bacterial vaginosis and Mycoplasma hominis. J. Infect. Dis. 191, 25-32. doi: 10.1086/426394

Sherrard, J., and Barlow, D. (1996). Gonorrhoea in men: clinical and diagnostic aspects. Genitourin. Med. 72, 422-426. doi: 10.1136/sti.72.6.422
Spurbeck, R. R., and Arvidson, C. G. (2010). Lactobacillus jensenii surfaceassociated proteins inhibit Neisseria gonorrhoeae adherence to epithelial cells. Infect. Immun. 78, 3103-3111. doi: 10.1128/IAI.01200-09

Srinivasan, S., Hoffman, N. G., Morgan, M. T., Matsen, F. A., Fiedler, T. L., Hall, R. W., et al. (2012). Bacterial communities in women with bacterial vaginosis: high resolution phylogenetic analyses reveal relationships of microbiota to clinical criteria. PLoS One 7:e37818. doi: 10.1371/journal.pone. 0037818

Tachedjian, G., Aldunate, M., Bradshaw, C. S., and Cone, R. A. (2017). The role of lactic acid production by probiotic Lactobacillus species in vaginal health. Res. Microbiol. 168, 782-792. doi: 10.1016/j.resmic.2017.04.001

Tamarelle, J., Thiebaut, A. C. M., de Barbeyrac, B., Bebear, C., Ravel, J., and Delarocque-Astagneau, E. (2019). The vaginal microbiota and its association with human papillomavirus, Chlamydia trachomatis, Neisseria gonorrhoeae and Mycoplasma genitalium infections: a systematic review and meta-analysis. Clin. Microbiol. Infect. 25, 35-47. doi: 10.1016/j.cmi.2018.04.019

Tuddenham, S., Ravel, J., and Marrazzo, J. M. (2021). Protection and risk: male and female genital microbiota and sexually transmitted infections. J. Infect. Dis. 223, S222-S235. doi: 10.1093/infdis/jiaa762

van de Wijgert, J., and Verwijs, M. C. (2020). Randomized trial of lactin-V to prevent recurrence of bacterial vaginosis. N. Engl. J. Med. 383, 790-791. doi: $10.1056 /$ nejmc2021832

van der Veer, C., Bruisten, S. M., van der Helm, J. J., de Vries, H. J., and van Houdt, R. (2017). The cervicovaginal microbiota in women notified for chlamydia trachomatis infection: a case-control study at the sexually transmitted infection outpatient clinic in Amsterdam. Neth. Clin. Infect. Dis. 64, 24-31. doi: 10.1093/ cid/ciw586

Vielfort, K., Sjolinder, H., Roos, S., Jonsson, H., and Aro, H. (2008). Adherence of clinically isolated lactobacilli to human cervical cells in competition with Neisseria gonorrhoeae. Microbes Infect. 10, 1325-1334. doi: 10.1016/j.micinf. 2008.07.032

Wiesenfeld, H. C., Hillier, S. L., Krohn, M. A., Landers, D. V., and Sweet, R. L. (2003). Bacterial vaginosis is a strong predictor of Neisseria gonorrhoeae and Chlamydia trachomatis infection. Clin. Infect. Dis. 36, 663-668. doi: 10.1086/ 367658

Wiesenfeld, H. C., Hillier, S. L., Meyn, L. A., Amortegui, A. J., and Sweet, R. L. (2012). Subclinical pelvic inflammatory disease and infertility. Obstet. Gynecol. 120, 37-43. doi: 10.1097/AOG.0b013e31825a6bc9

Witkin, S. S., and Linhares, I. M. (2017). Why do lactobacilli dominate the human vaginal microbiota? BJOG 124, 606-611. doi: 10.1111/1471-0528. 14390

Zhou, X., Brown, C. J., Abdo, Z., Davis, C. C., Hansmann, M. A., Joyce, P., et al. (2007). Differences in the composition of vaginal microbial communities found in healthy Caucasian and black women. ISME J. 1, 121-133. doi: 10.1038/ismej. 2007.12

Conflict of Interest: The authors declare that the research was conducted in the absence of any commercial or financial relationships that could be construed as a potential conflict of interest.

Publisher's Note: All claims expressed in this article are solely those of the authors and do not necessarily represent those of their affiliated organizations, or those of the publisher, the editors and the reviewers. Any product that may be evaluated in this article, or claim that may be made by its manufacturer, is not guaranteed or endorsed by the publisher.

Copyright (c) 2022 Lovett, Seña, Macintyre, Sempowski, Duncan and Waltmann. This is an open-access article distributed under the terms of the Creative Commons Attribution License (CC BY). The use, distribution or reproduction in other forums is permitted, provided the original author(s) and the copyright owner(s) are credited and that the original publication in this journal is cited, in accordance with accepted academic practice. No use, distribution or reproduction is permitted which does not comply with these terms. 